\title{
Eficacia de biofungicidas para el manejo de la costra negra (Rhizoctonia solani Kühn) de la papa en Nariño, Colombia
}

\author{
Carlos A. Betancourth ${ }^{1 *}$, Benjamín A. Sañudo ${ }^{2}$, Carlos A. Flórez ${ }^{2}$ y Claudia E. Salazar ${ }^{1}$ \\ (1) Facultad de Ciencias Agrícolas, Dpto. de Producción y Sanidad vegetal, Univ. de Nariño. Pasto, Colombia \\ (correo-e: cbet70@yahoo.com; claudiasalazarg@udenar.edu.co). \\ (2) Grupo de investigación de Sanidad Vegetal (GRISAV), Univ. de Nariño. Pasto, Colombia \\ (correo-e: cflorezcasanova@outlook.com) \\ ${ }^{*}$ Autor a quien debe ser dirigida la correspondencia
}

Recibido Jul. 22, 2021; Aceptado Sep. 29, 2021; Versión final Oct. 28, 2021, Publicado Feb. 2022

\begin{abstract}
Resumen
Este estudio evaluó el efecto de biofungicidas sobre el manejo del hongo patógeno Rhizoctonia solani Kühn en el cultivo de papa en tres localidades de Nariño (Colombia). En lotes con alta incidencia de la enfermedad rizoctoniasis (costra negra), se estableció un diseño experimental de bloques completos al azar y tres repeticiones. Los tratamientos correspondieron a: un testigo (T1), el control químico Pentiopirad (T2), Trichoderma spp. (T3), Bacillus subtilis (T4), Pseudomonas aeruginosa (T5), y el bioestimulante Nointox® (T6). Se presentaron diferencias estadísticas con respecto al testigo, logrando menor incidencia durante las etapas de brotación y tuberización. Los rendimientos con los valores más altos se presentaron en la localidad de Santa Ana de Túquerres (Nariño, Colombia), resultados probablemente influenciados por el ambiente. Se concluye que el fungicida Pentiopirad, Trichoderma spp. y B. subtilis presentan características promisorias para el manejo de $R$. solani en el cultivo de papa.
\end{abstract}

Palabras clave: papa; biocontrol; micoparasitismo; pentiopirad; costra negra; Rhizoctonia solani Kühn

\section{Efficacy of biofungicides on managing potato black scurf (Rhizoctonia solani Kühn) in Nariño, Colombia}

\begin{abstract}
This research study assessed the efficacy of biofungicides for managing the pathogenic fungus Rhizoctonia solani Kühn in potato crops at three different sites in the state of Nariño (Colombia). A randomized complete block experimental design with three replicates was performed in plots with a high incidence of rhizoctoniasis disease (black scurf). The treatments included a control (T1), Penthiopyrad chemical control (T2), Trichoderma spp. (T3), Bacillus subtilis (T4), Pseudomonas aeruginosa (T5), and the biostimulant Nointox® (T6). The results showed significant differences between treatments and the control, achieving a lower incidence of rhizoctoniasis disease during sprouting and tuberization stages. Yields were highest at the Santa Ana de Tuquerres (Nariño, Colombia) site, but this may be due to environmental factors. It is concluded that the fungicide Pentiopirad, Trichoderma spp., and Bacillus subtilis showed the most promising features for managing $R$. solani in potato crops.
\end{abstract}

Keywords: potato; biocontrol; mycoparasitism; penthiopyrad; black scurf; Rhizoctonia solani Kühn 


\section{INTRODUCCIÓN}

La papa (Solanum tuberosum) es el cuarto alimento más importante en el mundo. En Colombia su producción aporta el $3.3 \%$ del PIB Agropecuario Nacional y se concentra principalmente en nueve departamentos. Nariño contribuye el $21 \%$ de la producción nacional en 24906 hectáreas sembradas y 578695 toneladas de papa al año con variedades blancas, mamberas y criollas que abastecen las demandas del mercado interno y nacional (FEDEPAPA, 2020). Sin embargo, la producción puede verse comprometida por fitopatógenos transmitidos por el suelo los cuales llegan a ocasionar pérdidas directas de rendimiento y calidad (Fiers et al., 2012). Una enfermedad grave es la costra negra causada por el hongo Rhizoctonia solani, la cual tiene lugar en la mayoría de zonas que cultivan el tubérculo en el mundo; puede atacar al cultivo desde etapas tempranas en la emergencia afectando los brotes, durante el crecimiento vegetativo ocasionando lesiones en estolones y tallos, así como en la postcosecha al formar esclerocios en la epidermis de los tubérculos cosechados (Tsror, 2010). En papa $R$. solani normalmente es un patógeno necrotrófico; durante el proceso de patogenia se ha determinado genes que codifican enzimas hidrolasas y peptidasas que actúan sobre componentes de la pared celular, igualmente genes con el probable rol putativo de expresar moléculas efectoras para apoyar el reconocimiento y la colonización del agente causal durante la interacción temprana con su anfitrión (Zrenner et al., 2020).

Desde inicio del nuevo milenio, en el departamento de Nariño (Colombia) hay preocupación por la creciente incidencia de la costra negra de papa en sistemas de producción a mediana y gran escala, que potencialmente puede reducir hasta un $43 \%$ del rendimiento (Salazar et al., 2002). En Colombia, el grupo de anastomosis predominante es AG -3PT (tipo papa) siendo el principal agente causal del cancro del tallo y la costra negra de la papa. En el departamento de Nariño, además de $R$. solani AG3-PT, también se han identificado algunos asilamientos de Rhizoctonia binucleada (AG-A, AG-E y AG -I), cepas que se asocian con el chancro del tallo, sin embargo, se ha demostrado la posibilidad de que algunos de estos aislados puedan desencadenar respuestas de defensa en la planta debido a que causan una infección leve (Ferrucho et al., 2012).

Durante las últimas dos décadas en Nariño, el control de la enfermedad se realiza exclusivamente mediante el uso de fungicidas sintéticos con aplicaciones al suelo en el momento de la siembra y durante las etapas iniciales de crecimiento. Las moléculas pentiopirad, penfuflen y tifluzamida son las más utilizadas, todas ellas cuentan con igual mecanismo de acción, la inhibición de la enzima succinato deshidrogenasa en el proceso respiratorio (SDHI) (Walter, 2016). Esta práctica habitual y con resultados favorables, con el transcurrir del tiempo está mostrando pérdida de efectividad, relacionada quizá con el uso inadecuado, y deficiente rotación. Esto al parecer ha contribuido a cambios en las poblaciones del hongo y posible generación de resistencia, fenómeno aun no documentado para este caso particular. Sierotzki y Scalliet (2013), afirman que los fungicidas con acción específica como los SDHI tienen un riesgo medio a alto de generar resistencia.

Existen referencias sobre métodos alternativos del manejo de $R$. solani en el cultivo de papa, entre las cuales incluyen la incorporación de abonos verdes (Betancourth et al., 2021) y el empleo de biofungicidas. Estudios han determinado la capacidad antagónica de especies del hongo Trichoderma, como de las bacterias Bacillus y Pseudomonas frente a una amplia lista de fitopatógenos en diferentes cultivos (Tariq et al., 2020). En la acción de los agentes de control biológico se ha determinado la producción de antibióticos, sideróforos, enzimas bioactivos (metabolitos secundarios), competencia por nutrientes, promoción del crecimiento y desarrollo de la planta por la actividad de la microbiota rizosférica (Tariq et al., 2020).

Se destaca el efecto de biocontrol especies como Trichoderma koningiopsis, T. viride, T. hamatum, $T$. harzianum, $T$. koningii, $T$. asperellum y $T$. brevicompactum capaces de mitigar el ataque de patógenos como F. oxysporum, R. solani y P. capsici (Mousumi et al., 2019); en este mismo sentido, especies bacterianas presentes en los agroecosistemas y con utilidad para el control de enfermedades, se destacan Bacillus amyloliquefaciens, B. firmus, B. pumilus, B. cereus y B. subtilis (Villareal et al., 2018); también sobresalen cepas de Pseudomonas fluorescens y $P$. aeruginosa (Saikia et al., 2006). Varias cepas de estos microorganismos tienen la capacidad de disminuir el ataque de $R$. solani en papa, como lo afirman, García et al. (2012) y Arcos y Zúñiga (2015).

Actualmente, existen productos comerciales que incluyen unidades reproductivas de los microorganismos biocontroladores; así como de metabolitos activos y enzimas líticas (bioestimulantes), con efecto citotóxico sobre la fisiología de los fitopatógenos, en este contexto, se ha determinado que Trichoderma spp. son fuentes naturales de estas moléculas con actividad biológica (Al Abboud et al., 2014). De igual manera, se han registrado, productos a base de metabolitos secundarios producidos por bacterias acido lácticas (Lactobacillus sp.), entre los que se incluyen ácidos orgánicos, ácidos grasos de cadena corta, peróxido de hidrógeno, reuterina, diacetilo y bacteriocinas y sustancias inhibidoras similares a las bacteriocinas (Shehata et al., 2019). 
En el presente estudio se buscó evaluar la eficacia de biofungicidas, que incluyen aislamientos de Trichoderma spp., Bacillus subtilis, Pseudomonas aeruginosa y del producto natural a base de ácidos orgánicos y metabolitos secundarios (exoelicitores) de origen microbial (Nointox ${ }^{\circledR}$ ) en el manejo de R. solani en cultivos de papa localizados en tres localidades de Nariño.

\section{MATERIALES Y MÉTODOS}

El trabajo se realizó en las veredas Mapachico Centro del municipio de Pasto (2710 m.s.n.m; N 1¹6'53"/W

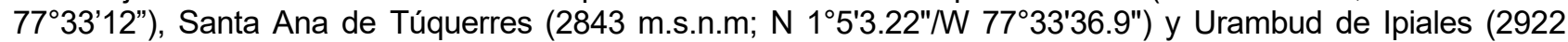
m.s.n.m; N $\left.0^{\circ} 50^{\prime} 56.6^{\prime \prime} / \mathrm{W} 77^{\circ} 39^{\prime} 16.1 "\right)$, en lotes establecidos previamente con papa por dos temporadas y con incidencias de costra negra de $60 \%, 35 \%$ y $42 \%$ respectivamente , valores cuantificados en el semestre anterior al establecimiento de la pruebas para la evaluación de los biofungicidas.

\section{Diseño experimental}

En cada localidad se estableció un diseño de bloques al azar con tres repeticiones y seis tratamientos, los cuales correspondieron a un testigo sin aplicación, un control químico (Pentiopirad), los biofungicidas comerciales Tribiol $₫$ (cepas de Trichoderma harzianum, T. koningii y T. viride), Bio-subtilis ${ }^{\circledR}$ (Bacillus subtilis), Pseudomonas (Pseudomonas aeruginosa) y el bioestimulante comercial Nointox® (metabolitos secundarios de origen microbial). Se utilizó una semilla certificada de la variedad Diacol Capiro. Las distancias de siembra fueron $1 \mathrm{~m}$ entre surcos y $0.40 \mathrm{~m}$ entre plantas sembrando un tubérculo por sitio. El área de la parcela experimental estuvo representada por cuatro surcos de $4 \mathrm{~m}$ de longitud, para un total de $16 \mathrm{~m}^{2}$, con 11 tubérculos por surco.

\section{Aplicación de los tratamientos}

De acuerdo a las recomendaciones de los distribuidores la dosis de aplicación estandarizada fue $3.75 \mathrm{cc}$ o g por litro de agua. Las aplicaciones del tratamiento se realizaron individualmente, dirigidas al suelo y procurando un buen humedecimiento del sitio sembrado, en tres momentos, en la siembra, en la emergencia total y al realizar el primer aporque, haciendo uso de una fumigadora manual con boquilla tipo cono lleno y una descarga promedio de $600 \mathrm{cc} / \mathrm{min}$.

\section{Manejo del cultivo de papa}

Después de la emergencia, se administró el fertilizante 13-26-6 (NPK) en cantidad de $500 \mathrm{~kg}$. ha-1. Posteriormente, en la etapa de formación de tallos aéreos junto con el primer aporque, se efectuó una segunda fertilización con 15-15-15 (NPK) en la misma cantidad, después de un mes se realizó un segundo aporque. Para el control de enfermedades limitantes como el tizón tardío ( $P$. infestans), se hizo una rotación entre fosetil aluminio (3 g. L-1), propamocarb (2 ml. $\left.\mathrm{L}^{-1}\right)$ y dimetomorfh $\left(2 \mathrm{~g} . \mathrm{L}^{-1}\right)$. Conjuntamente se empleó los insecticidas tiametoxan más lambdacihalotrina $\left(1.0 \mathrm{ml}\right.$. L-1), en rotación con dimetoato $\left(1.5 \mathrm{ml}^{-1} \mathrm{~L}^{-1}\right)$, thyociclan hidrogenoxalato $(1.5 \mathrm{ml}$. L-1), y metomyl $(2.0 \mathrm{ml}$. L-1), para el control de plagas de la parte aérea y subterránea, principalmente hacia $P$. vorax, $T$. solanivora, $P$. operculella, $A$. scarabaeoides y $P$. obsoleta, $T$. vaporariorum y F. tuberosi y T. palmi.

\section{Incidencia de Rhizoctonia solani}

Las evaluaciones se realizaron en los dos surcos centrales de cada parcela experimental. La incidencia de la enfermedad se determinó en dos tiempos, inicialmente en la etapa de brotación al finalizar la emergencia del cultivo alrededor de los 30 días después de la siembra, para lo cual se cuantifico la cantidad de plantas afectadas, las cuales presentaron emergencia tardía, asociada a la presencia de lesiones parciales o secamiento y muerte de brotes. Durante la floración que coincide con la etapa tuberización se determinó el número de plantas adultas con síntomas de enrollamiento foliar y madurez prematura a causa de la pudrición de raicillas y estolones. Para determinar la presencia de $R$. solani en las plantas sintomáticas, a partir de tejidos afectados se realizaron aislamientos en PDA siguiendo lo propuesto por Carling y Leiner (1986). El porcentaje de incidencia se determinó utilizando la fórmula:

$$
\% \text { Incidencia }=\frac{\text { Número de plantas totales }- \text { Número de plantas afectadas }}{\text { Número de plantas totales }} \times 100
$$

\section{Producción de tubérculos}

Con el fin de determinar el efecto de los tratamientos en la producción, las plantas se cosecharon individualmente y se realizó el conteo y pesaje de tubérculos grandes (>90 gramos) y medianos (50-80 g) por planta. El acumulado 
promedio de las dos categorías de peso determinó el rendimiento comercial de los tratamientos por planta, valores transformados a toneladas de papa / Ha.

\section{Análisis de datos}

Los datos obtenidos para la variable de incidencia y de rendimiento se evaluaron estadísticamente a través del análisis de varianza y la prueba de significancia de Tukey $(\alpha=0.05)$, de acuerdo con una distribución combinada de localidades bajo el diseño de bloques al azar, correspondiendo, las tres localidades al factor a y los seis tratamientos el factor $b$, siguiendo el modelo matemático:

$$
Y i j k=\mu+A j+B k(j)+T i+(T A) i j+e i j k
$$

\section{RESULTADOS Y DISCUSIÓN}

Los resultados del análisis de varianza de la Tabla 1, muestran diferencias significativas entre tratamientos para las variables incidencia de la enfermedad en las dos etapas evaluadas (brotación y tuberización), número de tubérculos grandes y para el rendimiento comercial. De igual forma existen diferencias estadísticas entre localidades para la incidencia de $R$. solani en la etapa de tuberización, así como para el numero de tubérculos grandes y medianos, e igualmente para el rendimiento comercial. Respecto a la interacción (tratamientos $x$ localidades), solamente el número de tubérculos medianos presento diferencias estadísticamente significativas.

Tabla 1: Análisis de varianza de las variables incidencia de Rhizoctonia solani, número y peso de tubérculos (kilos. planta ${ }^{-1}$ ) y rendimiento comercial $\left(\mathrm{t} . \mathrm{ha}^{-1}\right)$. ${ }^{*}$ Diferencias significativas $(\alpha 0.05) \mathrm{y}^{\text {ns }}$ Diferencias no significativas

\begin{tabular}{|l|c|c|c|c|c|c|c|}
\hline \multicolumn{1}{|c|}{ Fv } & Gl & \multicolumn{5}{c|}{ Cuadrado medio } & Valor de F \\
\hline & & \multicolumn{2}{|c|}{$\%$ Incidencia } & Número de tubérculos & & \\
\hline & & Brotación & Tuberización & Grandes & Medianos & Rendimiento comercial & \\
\hline Localidades & 2 & $6.64^{\mathrm{ns}}$ & $49.73^{*}$ & $0.32^{*}$ & $5.63^{*}$ & $112.37^{*}$ & 3.32 \\
\hline Tratamientos & 5 & $248.76^{*}$ & $249.38^{*}$ & $1.06^{*}$ & $0.23^{\mathrm{ns}}$ & $20.22^{*}$ & 2.53 \\
\hline $\begin{array}{l}\text { Tratamientos } \mathrm{x} \\
\text { Localidades }\end{array}$ & 10 & $28.24^{\mathrm{ns}}$ & $14.61^{\mathrm{ns}}$ & $0.04^{\mathrm{ns}}$ & $0.44^{*}$ & $1.53^{\mathrm{ns}}$ & 2.16 \\
\hline Error & 30 & 16.67 & 8.17 & 0.03 & 0.10 & 0.99 & \\
\hline
\end{tabular}

Incidencia de $R$. solani en la etapa de brotación

De acuerdo con la Tabla 2, para las localidades los ataques de $R$. solani en la etapa de brotación variaron de $11.04 \%$ a $12.12 \%$ sin diferencias significativas. Al observar los promedios generales de los tratamientos, la mayor afectación correspondió al testigo, el cual alcanzo un porcentaje de incidencia de la enfermedad del $21.22 \%$, con diferencias significativas respecto a los productos biológicos y molécula química (Pentiopirad), con medias entre 6.41 a $12.13 \%$. Además, en la localidad de Pasto, el porcentaje de plantas afectadas en el testigo fue similar al tratamiento de $P$. aeruginosa, y no se presentaron diferencias significativas entre los tratamientos en la localidad de Túquerres; esto probablemente está relacionado con la distribución inicial del inóculo en cada parcela (Tabla 2). No obstante, los resultados obtenidos muestran que el empleo del control químico, así como de productos formulados a base de microorganismos antagónicos logran menor la incidencia de la costra negra durante esta etapa crítica del cultivo.

De acuerdo con Tsror (2010), en la etapa inicial del cultivo de la papa, la incidencia del fitopatógeno produce lesiones necróticas en los extremos de los brotes (Figura 1), lo que resulta en inhibición o retraso de la emergencia, en la parte aérea se refleja en plantas débiles, con una disminución apreciable en el número de tallos, que al final representa pérdidas en los rendimientos. El desarrollo inicial del fitopatógeno en la fase de brotación del tubérculo esa condicionado en primer lugar por las condiciones edafoclimáticas, Brierley et al. (2016) informaron que las condiciones ambientales conducen a diferencias en el efecto patógeno de $R$. solani, independientemente de las características de virulencia y dispersión. Sin embargo, la fuente de inoculo juega un papel importante, según lo informado por Atkinson et al. (2010), puede ocurrir una infección inmediata cuando la semilla está contaminada, debido a la proximidad de los brotes salientes del tubérculo con la estructura infectiva del patógeno. 
Si bien los productos biológicos presentaron efectos similares al tratamiento químico, al presentar diferencias estadísticas y demuestra que la aplicación de estos tratamientos logro una protección de tubérculo en brotación frente al ataque inicial del hongo. Brierley et al. (2016), expone que una rápida emergencia reduce el ataque de $R$. solani, aun cuando existan altos niveles de inóculo.

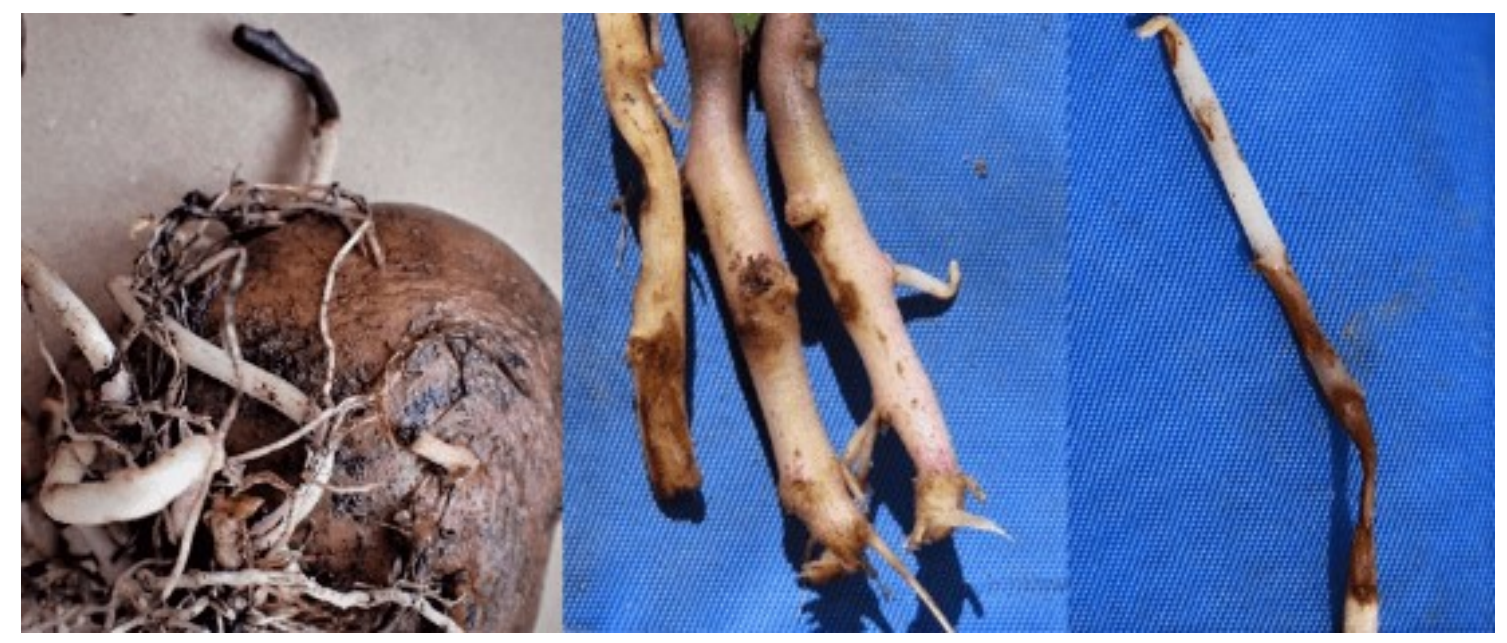

Fig. 1: Lesiones en brotes de papa Diacol Capiro causadas por Rhizoctonia solani

Los menores valores de incidencia temprana se presentaron con el uso de control químico, al respecto Kucharska et al. (2017) determinaron mediante pruebas de sensibilidad una eficacia promedio para inhibir el crecimiento de aislamientos de $R$. solani de $98.8 \%$ de Pentiopirad a una concentración del 0.25\% en PDA, aunque su efecto fungí toxico puede variar según la especie, la cepa y el grupo de anastomosis. En este mismo sentido, resultados obtenidos por Liu et al. (2021) en B. vulgaris, muestran que la aplicación a la semilla de Pentiopirad ofrece una protección temprana frente al ataque de $R$. solani y al realizar una posterior rotación con azoxistrobina durante el ciclo de cultivo mejora el control del fitopatógeno, además, la combinación de moléculas con diferente mecanismo de actuación puede retrasar el desarrollo de resistencia a los fungicidas.

La molécula de Pentiopirad pertenece a la familia química de las Carboxamidas o SDHI, al igual que thifluzamide se utilizan frecuentemente para el control de $R$. solani, su mecanismo es la inhibición de la succinato ubiquinoneoxidoreductasa, proteína clave para el proceso de respiración del hongo, ofreciendo un buen y rápido control de la enfermedad, sin embargo, este grupo de fungicidas tiene un riesgo potencial de generar resistencia cruzada, siendo probable que errores en la aplicación de estos fungicidas con actuación específica promueva la generación de mutantes resistentes de $R$. solani (Miao et al., 2020). El efecto supresor de los biofungicidas se fundamenta en sus formulaciones con efectiva concentración de unidades infecciosas, las cuales pueden tener rápido desarrollo y buena producción de metabolitos secundarios, ofreciendo posibilidades de biocontrol por acción de parasitismo, antibiosis o competencia o induciendo resistencia. Sin embargo, cuando se emplean unidades vivas como esporas o micelio el agente biocontrolador, pueden presentar limitantes en la adaptación y colonización de la rizosfera (Köhl et al. 2019).

\section{Incidencia de R. solani en la etapa de tuberización}

Para la incidencia en la etapa de tuberización se presentaron diferencias significativas para el factor de localidades, de manera específica entre los sectores de Pasto respecto a Ipiales (Tabla 1), presumiblemente las condiciones ambientales y textura del suelo favorecieron una mayor distribución del inóculo en suelo de la localidad de Ipiales (14.71\%) y los tratamientos tuvieron menor efecto supresor. Brierley et al. (2016), informa que la incidencia y severidad de la enfermedad está influenciada por la naturaleza dinámica de $R$. solani en el suelo, cuyo inoculo en forma miceliar o de esclerocios representa una importante consideración para el entendimiento del patosistema, y en el momento de plantear estrategias de manejo.

En lo concerniente a los promedios de los tratamientos, la incidencia en el testigo alcanzo el $19.90 \%$, estadísticamente superior a Pentiopirad, Tribiol $®$ y Bio-subtilis $®$; sin embargo, no difirió de Nointox ${ }^{\circledR}$ y $P$. aeruginosa, con una incidencia del $15.64 \%$ y $16.05 \%$ respectivamente (Tabla 2 ). Independientemente de la influencia del ambiente, las tres aplicaciones del fungicida Pentiopirad lograron el mejor control de $R$. solani. Analizando los valores en cada una de las localidades, de manera general se observó la menor incidencia con Pentiopirad, este tratamiento no presenta diferencias significativas con Tribiol $®$ o Bio-subtilis $®$ en Pasto e Ipiales. 
Tabla 2: Prueba de Tukey (a 0.05) para la incidencia de Rhizoctonia solani las etapas de brotación y tuberización. Letras iguales indican diferencias no significativas.

\begin{tabular}{|c|c|c|c|c|c|c|c|}
\hline \multicolumn{8}{|c|}{ Etapa de brotación } \\
\hline \multirow{2}{*}{ Localidades (a) } & \multicolumn{6}{|c|}{ Tratamientos (b) } & \multirow[b]{2}{*}{ Promedio a } \\
\hline & Testigo & Pentiopirad & Trlbiol $®$ & Bio-subtilis $®$ & $P$. aeruginosa & Nointox $®$ & \\
\hline Pasto & $22.73^{a}$ & $4.06^{b}$ & $7.58^{b}$ & $13.64^{b}$ & $7.58^{a b}$ & $10.61^{b}$ & $11.04^{a}$ \\
\hline Túquerres & $15.16^{a}$ & $7.58^{a}$ & 9.09 a & 9.09 a & $10.61^{a}$ & $15.16^{a}$ & $11.12^{a}$ \\
\hline Ipiales & $25.76^{a}$ & $7.58^{b}$ & $7.57^{b}$ & $12.13^{b}$ & $9.09^{b}$ & $10.61^{b}$ & $12.12^{a}$ \\
\hline Promedio de b & $21.22^{a}$ & $6.41^{b}$ & $8.08^{b}$ & $11.62^{b}$ & $11.83^{b}$ & $12.13^{b}$ & \\
\hline \multicolumn{8}{|c|}{${ }^{*}$ Tukey $0.05 b=5.98$} \\
\hline \multicolumn{8}{|c|}{ Etapa de tuberización } \\
\hline \multirow{2}{*}{ Localidades (a) } & \multicolumn{6}{|c|}{ Tratamientos (b) } & \\
\hline & Testigo & Pentiopirad & Trlbiol @ & Bio-subtilis $®$ & $P$. aeruginosa & Nointox $®$ & Promedio a \\
\hline Pasto & $21.15^{a}$ & $4.32^{c}$ & $9.73^{b c}$ & $3.75^{c}$ & $16.15^{a b}$ & $13.63^{a b}$ & $11.46^{b}$ \\
\hline Túquerres & $18.75^{a}$ & $4.57^{c}$ & $10.02^{b}$ & $11.55^{\mathrm{ab}}$ & $14.95^{a b}$ & $15.08^{a b}$ & $12.49 \mathrm{ab}$ \\
\hline Ipiales & $19.81^{a}$ & $7.15^{c}$ & $11.97^{a b c}$ & $14.08^{a b c}$ & $17.04^{a b}$ & $18.20 \mathrm{ab}$ & $14.71^{a}$ \\
\hline Promedio de b & $19.90^{a}$ & $5.35^{c}$ & $10.57^{b}$ & $9.79 \mathrm{bc}$ & $16.05^{a}$ & $15.64^{a}$ & \\
\hline
\end{tabular}

Aunque los efectos antagónicos de los productos microbianos que contienen Trichoderma spp. y $B$. subtilis fueron inconsistentes según el sector, la comparación de promedios generales permitió afirmar que el efecto de la bacteria es prometedor, por ser estadísticamente similar a los resultados del fungicida, corroborando lo señalado por Ben Khedher et al. (2020), sobre la capacidad de biocontrol de esta bacteria, cuyos resultados concluyen que la cepa de $B$. subtilis V26 presenta una supresión significativa de las lesiones en la raíz y estolones, además restringe la colonización del tubérculo por la costra negra. Los mismos investigadores afirman, que la bacterialización suelo con $B$. subtilis restringe el desarrollo de $R$. solani, debido a la presencia de metabolitos volátiles con efecto antifúngico en la rizosfera.

Villareal et al. (2018) mencionan que el efecto antifúngico de $B$. subtilis ocurre al liberar en el suelo metabolitos secundarios, en su mayoría lipopéptidos de bajo peso molecular, con un efecto biosurfactante que desencadena la desestabilización de membranas biológicas de fitopatógenos. Arcos y Zúñiga (2015) corroboraron el efecto positivo de $B$. subtilis contra $R$. solani en cultivos de papa mediante antagonismo o induciendo la resistencia sistémica. Hussain y Khan (2020), registran que $B$. subtilis proporciona un efecto protector sobre sus hospedadores mediante la estimulación de respuestas frente al estrés biótico; sustancias como las surfactinas y las fengicinas se han categorizado como inductores de resistencia que actúan individualmente o en sinergia con otros lipopéptidos. Asimismo, las bacterias del género Bacillus han mostrado un efecto positivo sobre el desarrollo y crecimiento de plantas de papa bajo condiciones controladas.

En la localidad de Túquerres se obtuvieron resultados prometedores con el uso del biofungicida cuya materia activa eran las especies de Trichoderma, tratamiento que en los promedios generales no presenta diferencias significativas con B. subtilis. García et al. (2012), reportaron que el hongo Trichoderma inoculado en las etapas iniciales puede reducir significativamente la incidencia y severidad de Rizoctoniasis en cultivos de papa. Abbas et al. (2017) explican que las especies de Trichoderma realizan su acción de biocontrol a través de tres tipos de mecanismos, competencia directa por espacio o nutrientes, producción de metabolitos antibióticos volátiles o no volátiles y micoparasitismo directo.

Especies como $T$. harzianum han presentado una alta actividad antagonista e hiperparasitaria contra Rhizoctonia sp., igualmente cepas de $T$. viride limitan el desarrollo de patógenos del suelo tales como $R$. solani, Fusarium spp., Sclerotium rolfsii durante ensayos in vitro igualmente, estos fitopatógenos también 
muestran susceptibilidad a $T$. koningii así como a otras especies micoparasitarias y productoras de metabolitos secundarios (Garrido y Vilela, 2019). También se ha determinado un efecto inhibidor significativo de $T$. virens sobre $R$. solani, asociado con genes para el hiperparasitismo y la antibiosis, que incluyen proteasas extracelulares, transportadores de oligopéptidos, receptores acoplados a proteína G, quitinasas, glucanasas, proteasas, proteínas de resistencia a la tetraciclina y reductasas (Halifu et al., 2020).

\section{Tubérculos por planta}

El análisis de varianza determinó diferencias significativas entre sectores y tratamientos, en la variable número de tubérculos grandes y medianos por planta, esta última categoría presento diferencias estadísticas para interacción localidades por tratamientos (Tabla 1). Los mayores valores de producción de tubérculos grandes por planta se obtuvieron en Tuquerres con diferencias significativas respecto a Pasto e Ipiales, los cuales también presentan resultados estadísticos diferentes entre sí (Tabla 3); esta situación se debe principalmente a las condiciones ambientales en lugar del efecto directo de la incidencia del fitopatógeno.

El efecto de la aplicación de los tratamientos, tanto en la comparación de los promedios generales, como los obtenidos en cada municipio, mostró que con la aplicación del fungicida pentiopirad se obtuvo la mayor cantidad de tubérculos grandes, mientras que la reducción más considerable correspondió al testigo. Además, los resultados muestran el comportamiento promisorio de $B$. subtilis, con diferencias no significativas respecto al tratamiento químico (Tabla 3). El comportamiento de Trichoderma spp. fue sobresaliente porque superó al testigo, Pseudomonas aeuroginosa y Nointox ${ }^{\circledR}$, aunque no fue consistente en los tres sectores debido a que hay diferencias en la acción antagónica, posiblemente por las especies a las que componen el producto.

Lo observado en esta investigación permite asegurar que la protección en papa es necesaria para el caso de $R$. solani, siendo necesaria la implementación de un enfoque de manejo integrado de la enfermedad y el conocimiento de las diferentes etapas del ciclo patogénico (Tsror, 2010). Existe una relación entre la protección que brinda el control químico y la bacteria $B$. subtilis hasta la etapa de tuberización sobre la producción de tubérculos grandes, debido al menor ataque de $R$. solani sobre la muerte de brotes, necrosis de estolones y pudrición de extremos radicales, permitiendo condiciones para un completo desarrollo de tubérculos formados y una mayor eficiencia en la absorción de nutrientes (Brierley et al., 2016). Respecto a la comparación de promedios de tubérculos medianos (Tabla 3), los menores rendimientos se obtuvieron en la localidad de Pasto, donde una mayor incidencia de $R$. solani en la fase temprana de cultivo afectó la formación de los tallos productivos, provocando la formación de un extenso sistema de raíces (Atkinson et al., 2010). La localidad de Túquerres presentó un mayor promedio para esta variable, posiblemente por las condiciones ambientales, ya que no hubo diferencias entre tratamientos (Tabla 3).

Cuando se afecta el sistema radicular y vascular, aspectos como la nutrición se limitan, generando anomalías como plantas débiles, con desigualdad en el crecimiento, enrollamiento foliar, secamiento de ramas, formación de tubérculos aéreos y, por tanto, disminución de los rendimientos (Tsror, 2010). Infecciones en estolones jóvenes ocasionan un descenso en el número de tubérculos, así como formación de tubérculos pequeños y deformes cerca del tallo (Atkinson et al., 2010). Para lograr una protección de la papa contra $R$. solani es necesario suprimir el inoculo inicial (semilla y suelo), y fortalecer la microbiota benéfica del suelo, donde se destaca el uso de antagonistas con posibilidad de colonizar la rizosfera, y lograr inhibición de fitopatógenos, además beneficiar el crecimiento y desarrollo vegetal (Köhl et al. 2019).

Los resultados permiten inferir que los productos biológicos comerciales logran mayor número de tubérculos, en especial de tamaño grande, sin embargo, los tratamientos de $P$. aeruginosa y Nointox $®$ no presentaron un efecto diferencial en la formación y llenado de tubérculos respecto al testigo. Esta situación asociada con el factor ambiental, aunque existe la probabilidad de que la cepa de la especie bacteriana no expreso su potencial de biocontrol sobre $R$. solani; en este mismo sentido, el bioestimulante a base de ácidos orgánicos y exoelicitores (Nointox ${ }^{\circledR}$ ), presento efectos indiferentes frente a la infección del hongo.

No obstante, respecto a $P$. aeruginosa Saikia et al. (2006) demostraron que el tratamiento de semillas de arroz con esta especie logró una actividad promotora del crecimiento e induce resistencia sistémica frente al ataque de $R$. solani AG5 involucrando la producción de ácido salicílico y peroxidasas, además permitió mayor rendimiento del grano. De manera similar, Tomar et al. (2019) determinó que el porcentaje de inhibición de aislados de $P$. aeruginosa oscila entre el 45.5 y $54.6 \%$, sin embargo, concluyen que la bacteria y sus metabolitos tienen una escaza capacidad de suprimir la enfermedad de la costra negra de la papa en campo. Por otra parte, Al Abboud, et al. (2014) describen los beneficios del empleo de bioestimulantes, entre los cuales se han descrito la reducción de la severidad de enfermedades, varios de estos productos incluyen enzimas o metabolitos secundarios involucrados en la acción biocontroladora; la aplicación continua de estos productos, podría tener un efecto a largo plazo beneficioso para las poblaciones de agentes de biocontrol y mantener su eficacia. 
Tabla 3: Prueba de Tukey ( $\alpha$ 0.05) para número de tubérculos grandes y medianos por planta. Letras iguales indican diferencias no significativas

\begin{tabular}{|c|c|c|c|c|c|c|c|}
\hline \multicolumn{8}{|c|}{ Tubérculos grandes por planta } \\
\hline \multirow{2}{*}{ Localidad (a) } & \multicolumn{6}{|c|}{ Tratamientos (b) } & \multirow[b]{2}{*}{ Promedio a } \\
\hline & Testigo & Pentiopirad & Trlbiol $®$ & Bio-subtilis $®$ & $P$. aeruginosa & Nointox $®$ & \\
\hline Pasto & $1.90^{c}$ & $2.86^{a}$ & $2.49^{b}$ & $2.72 \mathrm{ab}$ & $2.14^{\mathrm{c}}$ & $2.01^{\mathrm{c}}$ & $2.35^{b}$ \\
\hline Túquerres & $2.16^{\mathrm{c}}$ & $2.91^{a}$ & $2.46^{b c}$ & $2.59 \mathrm{ab}$ & $2.40 \mathrm{bc}$ & $2.29 \mathrm{bc}$ & $2.47^{\mathrm{a}}$ \\
\hline Ipiales & $1.62^{c}$ & $2.63^{a}$ & $2.33 \mathrm{ab}$ & $2.60^{a}$ & $2.03^{b}$ & $1.99^{c}$ & $2.20^{c}$ \\
\hline Promedio de b & $1.89^{d}$ & $2.80^{a}$ & $2.43^{b}$ & $2.64^{\mathrm{a}}$ & $2.19^{c}$ & $2.10^{\mathrm{c}}$ & \\
\hline \multicolumn{8}{|c|}{${ }^{*}$ Tukey $0.05 a=0.11 ;$ Tukey $0.05 b=0.20$} \\
\hline \multicolumn{8}{|c|}{ Tubérculos medianos por planta } \\
\hline \multirow{2}{*}{ Localidad (a) } & \multicolumn{6}{|c|}{ Tratamientos (b) } & \\
\hline & Testigo & Pentiopirad & Trlbiol $\circledast$ & Bio-subtilis $®$ & $P$. aeruginosa & Nointox $®$ & Promedio a \\
\hline Pasto & $3.24^{\mathrm{a}}$ & $2.95^{a b}$ & $2.72^{a b}$ & $2.68^{a b}$ & $2.46^{b}$ & $3.01^{b}$ & $2.84^{c}$ \\
\hline Túquerres & $3.48^{\mathrm{a}}$ & $3.88^{a}$ & $4.14^{\mathrm{a}}$ & $4.13^{a}$ & $3.86^{a}$ & $3.93^{\mathrm{a}}$ & $3.90^{a}$ \\
\hline Ipiales & $3.43^{\mathrm{ab}}$ & $4.16^{\mathrm{a}}$ & $4.14^{\mathrm{a}}$ & $3.63^{\mathrm{ab}}$ & $3.85^{a}$ & $2.88^{b}$ & $3.68^{b}$ \\
\hline Promedio de b & $3.38^{\mathrm{a}}$ & $3.66^{\mathrm{a}}$ & $3.67^{\mathrm{a}}$ & $3.48^{\mathrm{a}}$ & $3.39^{a}$ & $3.27^{\mathrm{a}}$ & \\
\hline
\end{tabular}

\section{Rendimiento comercial}

Para esta variable el análisis de varianza (Tabla 1), se encontraron diferencias significativas entre sectores y tratamientos. Los mayores rendimientos fueron para las localidades de Tuquerres e Ipiales con más de $15 \mathrm{t}$. ha $^{-1}$, mostrando diferencias significativas con relación al sector de Pasto, donde la producción papa comercial fue de 11.458 t. ha-1, y los tratamientos no presentaron diferencias significativas (Tabla 4). Esta menor producción provocada por la infestación general de $R$. solani en las etapas de emergencia y tuberización, a pesar de que esta la localidad presentó los menores valores promedio de incidencia de plantas sintomáticas (Tabla 2). Igualmente, el rendimiento comercial estuvo influenciado por la fertilidad del suelo y las condiciones climáticas, que también influyeron en la respuesta del cultivo frente a la enfermedad.

De acuerdo con Atkinson et al. (2010), el ataque de R. solani sobre estolones afecta el proceso de tuberización, ocurriendo cambios en los tubérculos respecto a tamaño, número y forma, por ende, la producción comercial. Sin embargo, el aspecto más agravante de la enfermedad acaece sobre el perfil del tamaño del tubérculo y la pérdida de calidad debido a la costra negra, aun cuando se han estimado pérdidas superiores al 30\% de los rendimientos (Tsror, 2010).

En la comparación de los promedios generales para el factor de los tratamientos, se determina que el rendimiento comercial en el testigo fue significativamente menor que los obtenidos con pentiopirad, Tribiol $\mathbb{R}$ y Bio-subtilis $®$, tratamientos que no tuvieron diferencias significativas entre sí y superan en más de dos toneladas por hectárea al testigo. Los resultados positivos obtenidos con la aplicación de Trichoderma spp. y $B$. subtilis reconocen la acción favorable de estos agentes de biocontrol contra $R$. solani en cultivos de papa. Köhl, et al. (2019), describió la eficacia biológica de las especies de Trichoderma y Bacillus como alternativas para el control biológico de enfermedades en las plantas, que se pueden implementar en programas de agricultura sostenible, así como planes de manejo integrado en agricultura convencional, debido a su capacidad para inhibir fitopatógenos, promover el crecimiento e inducir resistencia en sus hospedadores. 
Tabla 4: Prueba de Tukey ( $\alpha$ 0.05) para el rendimiento comercial en toneladas por hectárea (t. ha-1). Letras iguales indican diferencias no significativas.

\begin{tabular}{|c|c|c|c|c|c|c|c|}
\hline \multirow{2}{*}{ Localidad (a) } & \multicolumn{7}{|c|}{ Tratamientos (b) } \\
\hline & Testigo & Pentiopirad & Trlbiol $®$ & Bio-subtilis $®$ & P. aeruginosa & Nointox ${ }^{\circledR}$ & Promedio a \\
\hline Pasto & $10.19^{a}$ & $12.75^{a}$ & $11.98^{a}$ & $12.08^{a}$ & $10.35^{a}$ & $11.45^{a}$ & $11.45^{b}$ \\
\hline Tuquerres & $13.12^{b}$ & $17.71^{a}$ & $17.45^{\mathrm{a}}$ & $16.12^{a}$ & $15.14^{a b}$ & 15.99 bc & $15.92^{a}$ \\
\hline Ipiales & $13.29^{c}$ & $17.56^{a}$ & $18.16^{\mathrm{a}}$ & $16.21^{a b}$ & $14.32 \mathrm{bc}$ & $14.21^{b c}$ & $15.63^{a}$ \\
\hline Promedio b & $12.20^{c}$ & $16.01^{a}$ & $15.86^{a}$ & $14.78^{a b}$ & $13.27 \mathrm{bc}$ & $13.88^{b c}$ & \\
\hline
\end{tabular}

\section{CONCLUSIONES}

A partir de los resultados analizados estadísticamente y de las observaciones realizadas, se puede concluir: 1) La enfermedad causada por Rhizoctonia solani presentó una menor incidencia en la etapa de emergencia con el empleo de los productos biológicos y del fungicida pentiopirad en comparación con el testigo. 2) En la etapa de tuberización, el mejor efecto de control además de pentiopirad se logró con tres aplicaciones al suelo de Tribiol® (Trichoderma spp.) y Bio-subtilis ${ }^{\circledR}$ (Bacillus subtilis); 3) El uso de la bacteria Bacillus subtilis permitió rendimientos similares de papa variedad Diacol Capiro de primera categoría en comparación con fungicida pentiopirad; y 4) Las aplicaciones de Pentiopirad, Tribiol $®$ y Bio-subtilis $₫$ se obtuvieron rendimientos de papa comercial que superaron en más de dos toneladas por hectárea al obtenido en el tratamiento testigo.

\section{AGRADECIMIENTOS}

Esta investigación es un producto del Proyecto de investigación Manejo Integrado de la costra negra (Rhizoctonia solani Kühn) de la papa en el departamento de Nariño, financiado por la convocatoria 818 de Minciencias.

\section{REFERENCIAS}

Abbas, A., Jiang, D., y Fu, Y., Trichoderma spp. as Antagonist of Rhizoctonia solani, https://doi.org/10.1016/j.crvi.2019.05.002, J. Plant Pathol. Microbiol., 8(3), 1-9 (2017)

Al-Abboud, M. A., Ghany, T. A., y Alawlaqi, M. M., Role of biofertilizers in agriculture: a brief review, Mycopath, 11(2), 95$101(2014)$

Arcos, J., y Zúñiga, D., Efecto de Rizobacterias en el control de Rhizoctonia solani en el cultivo de papa, http://dx.doi.org/10.21704/rea.v14i1-2.86, Ecol. Apl., 14(2), 95-101 (2015)

Atkinson, D., Thornton, M. K., y Miller, J. S., Development of Rhizoctonia solani on stems, stolons and tubers of Potatoes I. Effect of inoculum source, https://doi.org/10.1007/s12230-010-9143-6, American Journal of Potato Research, 87(4), 374-381 (2010)

Ben-Khedher, S., Boukedi, H., Laarif, A., y Tounsi, S., Biosurfactant produced by Bacillus subtilis V26: a potential biological control approach for sustainable agriculture development, https://doi.org/10.1007/s13165-020-00316-0, Org. Agr., 10, 117-124 (2020)

Betancourth, C., Sañudo, B., Flórez, C., y Salazar, C., Manejo de la costra negra de la papa (Rhizoctonia solani) con el establecimiento de abonos verdes, http://dx.doi.org/10.4067/S0718-07642021000200165, Inf. Tecnol., 32(2), 165-174 (2021)

Brierley, J.L., Hilton, A.J., y otros tres autores, The Relative Importance of Seed- and Soil-Borne Inoculum of Rhizoctonia solani AG-3 in causing black scurf on potato, https://doi.org/10.1007/s11540-016-9320-1, Potato Res., 59, 181-193 (2016)

Carling, D.E., y Leiner, R.H., Isolation and Characterization of Rhizoctonia solani and Binucleate R. solani-like Fungi from Aerial Stems and Subterranean Organs of Potato Plants, https://doi.org/10.1094/Phyto-76-725, Phytopathology, 76(7), 725-729 (1986)

FEDEPAPA., Boletín Regional No. 05. Generalidades Departamentos, Federación Colombiana de Productores de Papa, https://fedepapa.com (2020)

Ferrucho, R. L., Cifuentes, J. M., Ceresini, P., y García, D. C., Rhizoctonia solani AG-3PT is the major pathogen associated with potato stem canker and black scurf in Colombia, Agron. Colomb., 30(2), 204-213 (2012) 
Fiers, M., Edel-Hermann, V., y otros cuatro autores, Potato soil-borne diseases. A review, https://doi.org/10.1007/s13593-011-0035-z, Agron. Sustain. Dev., 32, 93-132 (2012)

García, R., Arcia, M. A., Pérez, M. R., y Riera, R. F., Efecto de Trichoderma sobre el desarrollo de papa y el biocontrol de Rhizoctonia bajo tres tiempos de inicio de aplicación, Agron. Trop., 62, 1-4 (2012)

Garrido, M., y Vilela, N., Antagonistic capacity of Trichoderma harzianum compared to Rhizoctonia, Nakataea sigmoidea, Sclerotium rolfsii and its effect in native strains of Trichoderma isolated form rice crops, http://dx.doi.org/10.17268/sci.agropecu.2019.02.05, Scientia agropecuaria, 10(2), 199-206 (2019)

Halifu, S., Deng, X., y otros tres autores, Inhibitory Mechanism of Trichoderma virens ZT05 on Rhizoctonia solani, https://doi.org/10.3390/plants9070912, Plants, 9(7), 912 (2020)

Hussain, T., y Khan, A., Bacillus subtilis HussainT-AMU and its Antifungal activity against Potato Black scurf caused by Rhizoctonia solani on seed tubers, https://doi.org/10.1016/j.bcab.2019.101443, Biocatal. Agric. Biotechnol., 23, 101443 (2020)

Köhl, J., Kolnaar, R., y Ravensberg, W. J., Mode of action of microbial biological control agents against plant diseases: relevance beyond efficacy, https://doi.org/10.3389/fpls.2019.00845, Frontiers in Plant Science, 10, 845 (2019)

Kucharska, K., Katulski, B., y otros tres autores, Pathogenicity and Fungicide Sensitivity of Rhizoctonia solani and $R$. cerealis Isolates, Gesunde Pflanzen, doi:10.1007/s10343-017-0408-6, 70(1), 13-19 (2017)

Liu, Y., Qi, A., y otros tres autores, Combining Pentiopirad with azoxystrobin is an effective alternative to control seedling damping-off caused by Rhizoctonia solani on sugar beet, https://doi.org/10.1016/j.cropro.2020.105374, Crop Protection, 139, $105374(2021)$

Miao, J., Mu, W., y otros seis autores, Heterokaryotic state of a point mutation (H249Y) in SDHB protein drives the evolution of thifluzamide resistance in Rhizoctonia solani, https://doi.org/10.1002/ps.6155, Pest Management Science, 77(3), 1392-1400 (2021)

Mousumi, M., Haridasb, M., Sabua, A., Biological control of black pepper and ginger pathogens, Fusarium oxysporum, Rhizoctonia solani and Phytophthora capsici, using Trichoderma spp., https://doi.org/10.1016/j.bcab.2018.11.021, Biocatal. Agric. Biotechnol., 17, 177-183 (2019)

Saikia, R., Kumar, R., y otros tres autores, Pseudomonas aeruginosa inducing rice resistance against Rhizoctonia solani: production of salicylic acid and peroxidases, https://doi.org/10.1007/BF02931579, Folia Microbiol., 51(5), 375-380 (2006)

Salazar, C., Benavides, J., y Betancourth, C., Efecto de Rhizoctonia solani sobre la calidad y rendimiento de semilla de papa en el departamento de Nariño, Revista de Ciencias Agrícolas, 19(2), 105-121 (2002)

Shehata, M., Badr, A., y otros tres autores, Characterization of antifungal metabolites produced by novel lactic acid bacterium and their potential application as food biopreservatives, https://doi.org/10.1016/j.aoas.2019.05.002, Ann. Agric. Sci., 64, 71-78 (2019)

Sierotzki, H., y Scalliet, G., A review of current knowledge of resistance aspects for the next-generation succinate dehydrogenase inhibitor fungicides, doi: 10.1094/PHYTO-01-13-0009-RVW, Phytopathology, 103(9), 880-887 (2013)

Tariq, M., Khan, A., y otros cinco autores, Biological control: a sustainable and practical approach for plant disease management, https://doi.org/10.1080/09064710.2020.1784262, Acta Agric. Scand. - B Soil Plant Sci., 70(6), 507-524 (2020)

Tomar, S., Khan, M. A., Lal, M., y Singh, B. P., Efficacy of Biosurfactant Producing Bacteria (Pseudomonas aeruginosa) against Black Scurf (Rhizoctonia solani) of Potato, https://doi.org/10.5958/2249-524X.2019.00020.7, Pesticide Research Journal, 31(1), 126-128 (2019)

Tsror, L., Biology, epidemiology and management of Rhizoctonia solani on potato, https://doi.org/10.1111/j.14390434.2010.01671.x, Phytopathology, 158(10), 649-658 (2010)

Villarreal, M., Villa, E., Cira, L., y Estrada, M., The genus Bacillus as a biological control agent and its implications in the agricultural biosecurity, https://doi.org/10.18781/r.mex.fit.1706-5, Rev. Mex. Fitopatol., 36, 95-130 (2018)

Walter, H., Fungicidal succinate-dehydrogenase-inhibiting Carboxamides, In Bioactive carboxylic compound classes: pharmaceuticals and agrochemicals by C. Lamberth and J. Dinges, 405-425, John Wiley \& Sons, https://doi.org/10.1002/9783527693931.ch31, Weinheim, Germany (2016)

Zrenner, R., Genzel, F., y otros tres autores, Necrotrophic lifestyle of Rhizoctonia solani AG3-PT during interaction with its host plant potato as revealed by transcriptome analysis, https://doi.org/10.1038/s41598-020-68728-2, Sci. Rep., 10, 12574 (2020) 